\title{
Usability of the Level of the S100B Protein, the Gosling Pulsatility Index, and the Jugular Venous Oxygen Saturation for the Prediction of Mortality and Morbidity in Patients with Severe Traumatic Brain Injury
}

\author{
Ryszard Tomasiuk, ${ }^{1}$ Sebastian Dzierzęcki (iD, ${ }^{2,3}$ Artur Zaczyński, ${ }^{4}$ and Mirosław Ząbek ${ }^{2,3}$ \\ ${ }^{1}$ Kazimierz Pulaski University of Technology and Humanities Radom, Faculty of Medical Sciences and Health Sciences, \\ Radom, Poland \\ ${ }^{2}$ Department of Neurosurgery, Postgraduate Medical Centre, Warsaw, Poland \\ ${ }^{3}$ Gamma Knife Centre, Brodno Masovian Hospital, Warsaw, Poland \\ ${ }^{4}$ Clinical Department of Neurosurgery, Central Clinical Hospital of the Ministry of the Interior and Administration, \\ Warsaw, Poland
}

Correspondence should be addressed to Sebastian Dzierzęcki; sebastianneurochirurgia@gmail.com

Received 10 May 2021; Revised 16 September 2021; Accepted 22 September 2021; Published 25 October 2021

Academic Editor: Vida Demarin

Copyright (c) 2021 Ryszard Tomasiuk et al. This is an open access article distributed under the Creative Commons Attribution License, which permits unrestricted use, distribution, and reproduction in any medium, provided the original work is properly cited.

\begin{abstract}
The high frequency of traumatic brain injury imposes severe economic stress on health and insurance services. The objective of this study was to analyze the association between the serum S100B protein, the Gosling pulsatility index (PI), and the level of oxygen saturation at the tip of the internal jugular vein $(\mathrm{SjVO} \%)$ in patients diagnosed with severe TBI. The severity of TBI was assessed by a GCS score $\leq 8$ stratified by Glasgow outcome scale (GOS) measured on the day of discharge from the hospital. Two groups were included: GOS $<4$ (unfavorable group (UG)) and GOS $\geq 4$ (favorable group (UG)). S100B levels were higher in the UG than in the FG. PI levels in the UG were also substantially higher than in the FG. There were similar levels of SjVO2 in the two groups. This study confirmed that serum S100B levels were higher in patients with unfavorable outcomes than in those with favorable outcomes. Moreover, a clear demarcation in PI between unfavorable and FGs was observed. This report shows that mortality and morbidity rates in patients with traumatic brain injury can be assessed within the first 4 days of hospitalization using the S100B protein, PI values, and SjVO2.
\end{abstract}

\section{Introduction}

The leading global causes of death are traumatic brain injury (TBI), cardiovascular disease, and cancer [1].

TBI includes noncongenital tissue damage rendered by a sudden impact manifested by endocrine dysfunction, electrolyte imbalance, respiratory manifestations, and neurological, neuropsychological, and psychiatric dysfunction [2]. TBI occurs most frequently in two age groups: between 15 and 24 and older than 75 years of age [3]. Although TBI is prevalent internationally at 1.3 and 2 per 100,000 in North America and Europe, respectively, in Poland, its frequency oscillates around 0.07 per 100,000 . This high frequency of TBI imposes severe economic stress on health and insurance services due to costly and complicated treatment and rehabilitation processes [4-6].

Methods used for the diagnosis and treatment of TBI include the analysis of biochemical markers $[7,8]$, transcranial Doppler testing (TCD) [9], measurement of cerebral perfusion pressure (CPP) [10], the Glasgow Coma Scale (GCS) [11], and Marshall score [12].

To date, a variety of markers have been used to assess the severity of TBI, including lactate dehydrogenase [13], myelin alkaline protein [14], neuron-specific enolase [15], and 
creatine kinase [16]. However, none have been shown to be suitable for clinical practice. Recently, the S100B protein that is present in detectable concentrations in blood, serum, and cerebrospinal fluid (CSF) has attracted the interest of researchers. Its changes in serum level reflect the degree of posttraumatic brain damage, making it an adequate means for assessing the level of TBI [17-19]. S100B is crucial in intracellular processes of cell growth and metabolism [20], and its secretion induces autocrine and paracrine effects on glial cells, microglial cells, and neurons [21]. At micromolar concentrations, S100B induces apoptosis [18].

Other brain injury diagnosis methods include GCS, CPP, and TCD. Thus, GCS allows for an objective assessment of consciousness impairment in acute medical and trauma patients. TCD is a noninvasive technique that allows realtime monitoring of CPP, intracranial pressure (ICP), and cerebral blood flow (CBF). CPP is measured using the pulsatility index (PI) values of the middle cerebral artery (MCA). The CBF level is assessed using the mean blood flow velocity (MFV) [22].

Since the effectiveness of TBI treatment impacts patient outcome and reflects the quality of TBI diagnosis, there is ongoing research to find a "golden" TBI severity predictor or a method for quick and error-free diagnosis.

Considering the complexity of the problem and the continuing clinical demand, we conducted a study on the associations between serum S100B, PI, and the level of oxygen saturation at the tip of the internal jugular vein $\left(\mathrm{Sjv}_{2}\right)$ in patients diagnosed with severe TBI (defined by a GCS score $\leq 8)$.

\section{Methods}

2.1. Study Subjects. The Bioethics Committee of the Medical Center of Postgraduate Education in Warsaw approved the experimental protocols. All subjects or their guardians and if subjects were under 18, a parent and/or legal guardian signed an informed consent.

After admission to the Department of Neurosurgery and Trauma of the Nervous System, the patient's health was assessed using the GSC $[23,24]$. Each patient was also subjected to the standard diagnostic and therapeutic protocol in accordance with the European Consortium of Brain Injury Guidelines ([25] Patients with poor ventilation underwent a gasometric examination to optimize $\mathrm{pCO}_{2}$ (range $30-40 \mathrm{mmHg}$ ) and maintain hematocrit $(\mathrm{Ht})$ and hemoglobin $(\mathrm{Hb})$ levels at $30-40 \%$ and $12-14 \mathrm{~g} / \mathrm{dL}$, respectively.

Only patients with a GCS score $\leq 8$ were included in the study. The study group consisted of 60 patients ( 48 men and 12 women); the GCS and Marshall scale distributions are shown in Figure 1.

Venous blood samples $(5 \mathrm{~mL})$ were collected at admission and at 24-hour intervals for another $96 \mathrm{~h}$. Pretreated blood samples (clotted and centrifuged for $10 \mathrm{~min}$ at 1,000 $\mathrm{RPM}$ ) were stored at $-22^{\circ} \mathrm{C}$. Protein concentration measurements were performed using a Liason Sangtec 100 kit with a broad diagnostic spectrum of $0.02-30 \mu \mathrm{g} / \mathrm{L}$ and a sensitivity threshold of $0.02 \mu \mathrm{g} / \mathrm{L}$.

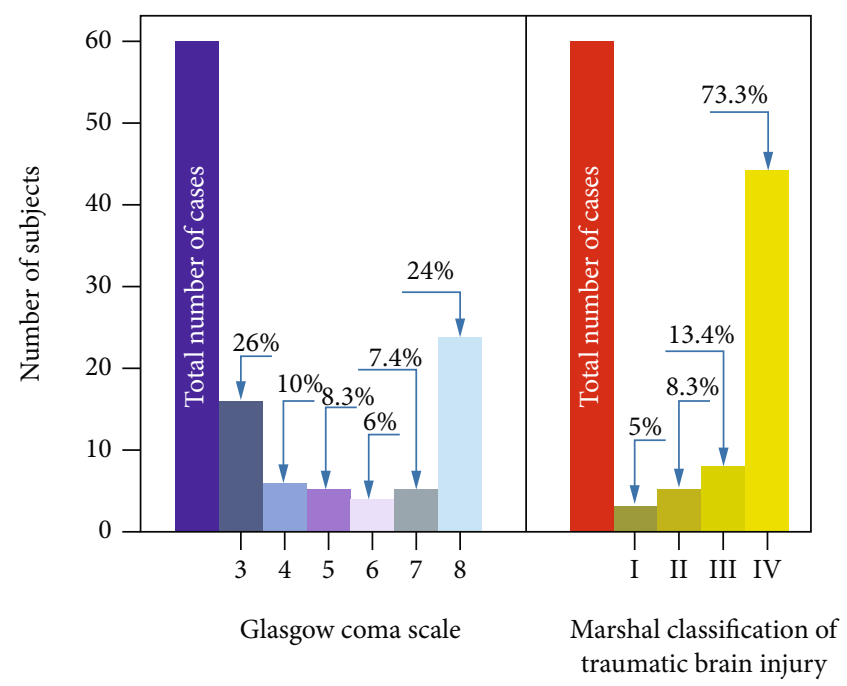

Figure 1: Graphical representation of patients admitted to the Medical Centre of Postgraduate Education. (a) Distribution of subjects GCS $\leq 8$. (b) Marshall classification of traumatic brain injury (MCTC) distribution. Numerals above the bars correspond to the number of specific cases (percentage of cases).

PI [26] was derived using a transcranial Doppler examination performed on a Mediasonic Transpect CDS Doppler in power motion mode TCD (PMD/TCD) at 24-hour intervals for $96 \mathrm{~h}$ after admission to the Neurosurgery Clinic. Initially, the arteries of the brain base accessible through the temporal window were scanned. Further analysis was completed on the middle cerebral arteries on the dominant lesion's side or the right side if the lesion's extent was symmetrical.

$\mathrm{SjvO} 2$ was determined in blood samples drawn from a catheter positioned in the jugular bulb using an oximeter (IL-284 CO-Oximeter; Instrumentation Laboratory, Lexington, MA).

The self-assessed S100B and PI reference ranges were determined using a group of 40 healthy volunteers: 25 men and 15 women with an average age of $47.0 \pm 14.77$ years (age range of 21 to 80 years).

2.2. Statistical Analysis. A sample normality was evaluated using the Shapiro-Wilk test [27]. Data are expressed as mean \pm standard deviation, with minimum and maximum values. Differences in the means of the study groups, i.e., "favorable" and "unfavorable," at specific times, were tested using a bootstrapped test for differences in means of 10,000 repeats with replacement [28]. Changes in S100B, $\mathrm{PI}$, and $\mathrm{SjvO} 2$ levels stratified by the study group were computed using the one-way Aligned Rank Transform for Nonparametric Factorial ANOVAs (ART) technique [29]. Because of the shortcomings of current statistical methods in handling advanced nonparametric statistics, we discuss only the outcome of one-way nonparametric factorial ANOVA. Patient mortality was taken into account by censoring the number of subjects in a group. The rate of change of a specific parameter was evaluated using the slope of a linear regression model. Values of $P<0.01$ were considered 
TABle 1: Changes in S-100b protein level stratified by GOS as a function of hospitalization time."UG” - "unfavorable” group, "FG" "favorable" group.

\begin{tabular}{|c|c|c|c|c|c|c|}
\hline outcome & measurement x 24 hrs & mean $(\mathrm{mg} / \mathrm{L})$ & STD (standard deviation) & $\min (\mathrm{mg} / \mathrm{L})$ & $\max (\mathrm{mg} / \mathrm{L})$ & $\mathrm{N}$ (number of subjects) \\
\hline \multirow{4}{*}{ UG } & 1 & 4.82 & 4.45 & 0.76 & 19.8 & 51 \\
\hline & 2 & 3.84 & 4.21 & 0.47 & 16.8 & 48 \\
\hline & 3 & 3.39 & 4.04 & 0.38 & 20.83 & 40 \\
\hline & 4 & 2.66 & 3.05 & 0.136 & 16.7 & 37 \\
\hline \multirow{4}{*}{ FG } & 1 & 1.01 & 0.29 & 0.71 & 1.6 & 9 \\
\hline & 2 & 0.84 & 0.21 & 0.62 & 1.3 & 9 \\
\hline & 3 & 0.83 & 0.35 & 0.51 & 1.51 & 9 \\
\hline & 4 & 0.61 & 0.24 & 0.39 & 1.1 & 9 \\
\hline
\end{tabular}

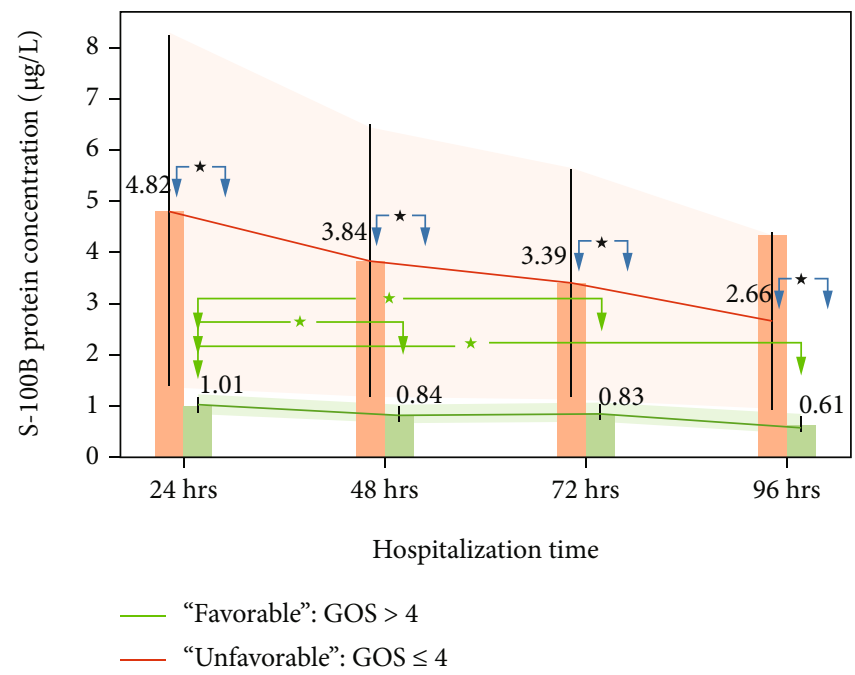

FIGURE 2: Changes in S100B protein level stratified by GOS as a function of hospitalization time. Whiskers represent the standard error; above the bar are the mean values at the specific time. Red arrows correspond to statistically significant changes between measurements at specific times in the "unfavorable" group. Green arrows correspond to statistically significant changes between measurements at specific times in the "favorable" group. Shaded regions correspond to $95 \%$ confidence intervals for the "unfavorable" group, red, and "favorable" group, green. * refers to $P<0.01$.

statistically significant. We conducted all analyses in the $\mathrm{R}$ programming language .

\section{Results}

This study was performed on two groups of patients stratified by GOS [30] and assessed on the day of discharge from the hospital. The UG consisted of patients with GOS $<4$. FG group encompassed patients with $\mathrm{GOS} \geq 4$. The stratification scheme led to the post hoc assignment of 51 and 9 patients to the UG and FG, respectively. The average age in the UG was 48 years (19-73) and 47 years (14-75) in the FG.

The standard reference range for serum S100B protein concentration was $0.05-0.23 \mu \mathrm{g} / \mathrm{L}$. The changes in the levels of the S100 protein of the studied groups (measured at 24, 48,72 , and $96 \mathrm{~h}$ after hospital admission) are compiled in Table 1 and Figure 2.

Figure 2 shows that S100B levels in UG were generally higher across all measurements than those in FG. In UG, a decreasing rate of $V_{\text {S100B_U }_{-}}=0.03 \mu \mathrm{g} / \mathrm{L} / \mathrm{h}$ was observed.
However, there were no statistically significant changes between consecutive measurements. In FG, statistically significant changes in S100B levels were observed between 24 and 48,24 and 72 , and 24 and $96 \mathrm{~h}$, and the rate of decrease in the S100B level was $V_{\text {S100B_F }}=-5.56 * 10^{-3} \mu \mathrm{g} / \mathrm{L} / \mathrm{h}$.

PI changes, which reflect cerebral flow, are compiled in Table 2 and Figure 3. We observed that PI levels in UG patients were substantially higher than in FG patients. Moreover, FG was defined by a decrease in PI level of $V_{\mathrm{PI} U}=-$ $9.58 * 10^{-3} / \mathrm{h}$ and the lack of statistically significant differences between consecutive measurements. In FG, statistically significant changes occurred between 24 and 48 and 24 and $72 \mathrm{~h}$ of hospitalization, and the rate of decrease in PI was $V_{\text {PL_F }}=-0.01 \mathrm{~cm} / \mathrm{s} / \mathrm{h}$. The relative ratio of the unfavorable to favorable group PI decrease rate was close to one: $V_{\text {PI_U }} / V_{\text {PI_F }}=9.58 * 10^{-3} / 10^{-2}=0.96$.

The fluctuations in $\mathrm{SjvO} 2 \%$ are shown in Table 3 and Figure 4 . The analysis of Figure 4 showed similar levels of $\mathrm{SjVO} 2$ in both groups. However, at 72 and $96 \mathrm{~h}$, the differences in SjvO2\% between UG and FG were statistically significant. The rate of decrease in $\mathrm{SjvO} 2 \%$ in $\mathrm{UG}$ was 
TABLE 2: Changes in PI stratified by GOS as a function of hospitalization time. UG" - "unfavorable" group, "FG" - "favorable" group.

\begin{tabular}{|c|c|c|c|c|c|c|}
\hline outcome & measurement $\times 24 \mathrm{hrs}$ & mean $(\mathrm{cm} / \mathrm{s})$ & STD (standard deviation) & $\min (\mathrm{cm} / \mathrm{s})$ & $\max (\mathrm{cm} / \mathrm{s})$ & $\mathrm{N}$ (number of subjects) \\
\hline \multirow{4}{*}{ UG } & 1 & 2.96 & 1.10 & 1.2 & 7.1 & 51 \\
\hline & 2 & 2.49 & 1.18 & 1.06 & 6.11 & 48 \\
\hline & 3 & 2.59 & 1.39 & 0.91 & 6.78 & 40 \\
\hline & 4 & 2.27 & 1.40 & 0.89 & 6.8 & 37 \\
\hline \multirow{4}{*}{ FG } & 1 & 1.78 & 0.16 & 1.5 & 2.11 & 9 \\
\hline & 2 & 1.30 & 0.17 & 1.1 & 1.6 & 9 \\
\hline & 3 & 1.17 & 0.26 & 0.91 & 1.8 & 9 \\
\hline & 4 & 0.98 & 0.31 & 0.63 & 1.6 & 9 \\
\hline
\end{tabular}

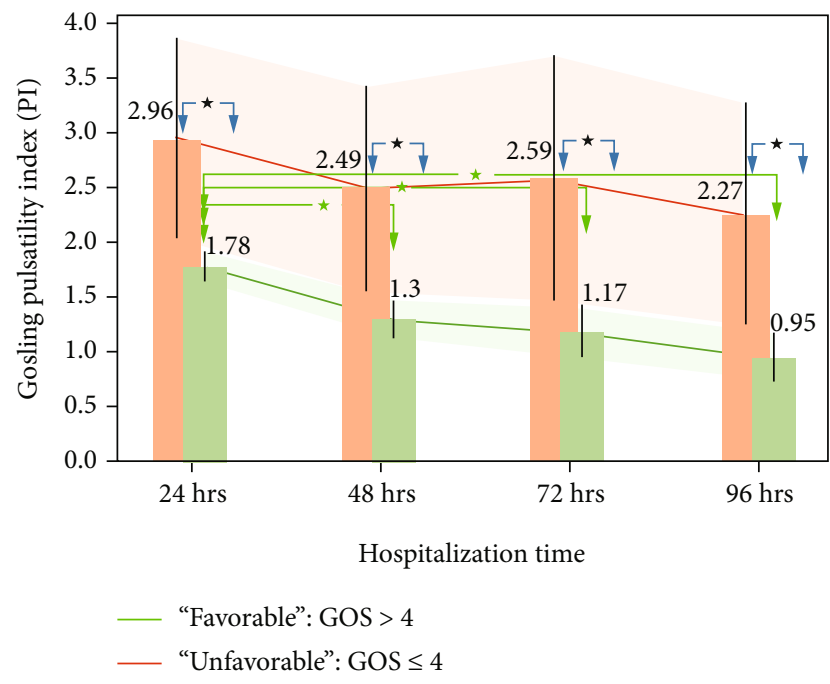

FIgURE 3: Changes in the Gosling pulsatility index (PI) stratified by GOS as a function of hospitalization time. Whiskers represent the standard error; above the bar are the mean values at the specific time. Red arrows correspond to statistically significant changes between measurements at specific times in the "unfavorable" group. Green arrows correspond to statistically significant changes between measurements at specific times in the "favorable" group. Shaded regions correspond to $95 \%$ confidence intervals for the "unfavorable" group, red, and "favorable" group, green. ${ }^{*}$ refers to $P<0.01$.

$V_{\text {SjvO2_U }}=-0.06 \% / \mathrm{h}$ and in $\mathrm{FG}$ was $V_{\text {SjvO2_F }}=-0.13 \% / \mathrm{h}$. The relative decrease rate of $\mathrm{SjvO} 2$ between the respective groups was 0.46 .

\section{Discussion}

TBI diagnosis and treatment methods are still insufficient and result in a mortality rate of 30-60\% [31-40]. In recent decades, the development of diagnostic techniques that exploit the physical and biochemical functions of the human body has led to the use of biochemical markers [7, 8], TCD [9], and CPP measurement [10] as the primary means of clinical diagnosis in patients with TBI.

To date, several analyses have been reported on the usability of S100B protein levels in assessing the severity of
TBI [41-44]. However, none performed a combined analysis of the levels of S100B protein, Gosling's pulsatility index, and jugular venous oxygen saturation for the prediction of mortality and morbidity among patients with TBI. To our knowledge, this study is a unique approach that allows for a more accurate assessment of the severity of TBI and prognosis related to the modality of treatment.

One study showed that $\mathrm{S} 100 \mathrm{~B}, V_{\text {mean }}$ levels, and SjvO2\% are verifiable TBI severity markers [35]. This study verified the usability of an early analysis, 1 to 4 days after hospital admission, of changes in $\mathrm{S} 100 \mathrm{~B}, V_{\text {mean }}$, and $\mathrm{SjvO} 2 \%$ levels for prognostic properties in clinical diagnosis. To overcome the limitation of this study caused by a small sample size, differences between studied groups were assessed by bootstrap analysis [45, 46]. Thus, through the introduction of 10,000 repeats in bootstrap analysis, we were able to achieve a good representation of the population according to the literature.

The study was performed on two samples stratified by GOS $<4$ (unfavorable group (UG)) and GOS $\geq 4$ (favorable group (FG)). The $26.6 \%$ mortality reported in this study was greater than the $13 \%$ reported by Gerber et al. [47]. Standard S100B levels oscillated between 0.05 and $0.23 \mu \mathrm{g} / \mathrm{L}$ and were considerably different from those previously reported as pathological [48].

Our results generally agree with the report by Raabe and Seifert [48], showing that serum levels of S100B are higher in patients with unfavorable outcomes than in those with favorable outcomes. However, we did not confirm an early stage increase in S100B levels in FG. Furthermore, this study showed that the increased levels of S100B in FG patients did not return to normal during the first four days of hospitalization and were on average $0.61 \mathrm{mg} / \mathrm{L}$ on day 4 . The decreasing rate of S100B levels in UG was equal to $5.655 \mu \mathrm{g} / \mathrm{L} / \mathrm{h}$, indicating that the nonpathological range might have been reached $153 \mathrm{~h}$ after hospital admission and $30 \mathrm{~h}$ longer than the value observed for FG. This observation indicates the presence of irreversible pathological changes that occur in brain tissue during the additional $30 \mathrm{~h}$ required to reach the reference range.

TCD allows the analysis of abnormalities in cerebral circulation in patients with TBI [22, 49-52] manifested by a decrease in $V_{\text {mean }}$ and an increase in PI $[53,54] . V_{\text {mean }}$ reference levels determined in this study [55] agreed with others [56-58] and defined the abnormal level of PI as 
TABLE 3: Changes in SjvO2 stratified by GOS as a function of hospitalization time. UG" - "unfavorable" group, "FG" - "favorable" group.

\begin{tabular}{|c|c|c|c|c|c|c|}
\hline outcome & measurement $\times 24 \mathrm{hrs}$ & mean $(\%)$ & STD (standard deviation) & $\min (\mathrm{cm} / \mathrm{s})$ & $\max (\mathrm{cm} / \mathrm{s})$ & $\mathrm{N}$ (number of subjects) \\
\hline \multirow{4}{*}{ UF } & 1 & 47.31 & 20.51 & 21 & 98 & 51 \\
\hline & 2 & 56.48 & 17.85 & 20 & 95 & 48 \\
\hline & 3 & 50.00 & 18.33 & 22 & 97 & 40 \\
\hline & 4 & 52.05 & 18.21 & 17 & 99 & 37 \\
\hline \multirow{4}{*}{ UG } & 1 & 54.11 & 13.23 & 37 & 69 & 9 \\
\hline & 2 & 58.11 & 6.68 & 49 & 72 & 9 \\
\hline & 3 & 64.00 & 8.89 & 51 & 81 & 9 \\
\hline & 4 & 63.57 & 8.06 & 50 & 73 & 7 \\
\hline
\end{tabular}

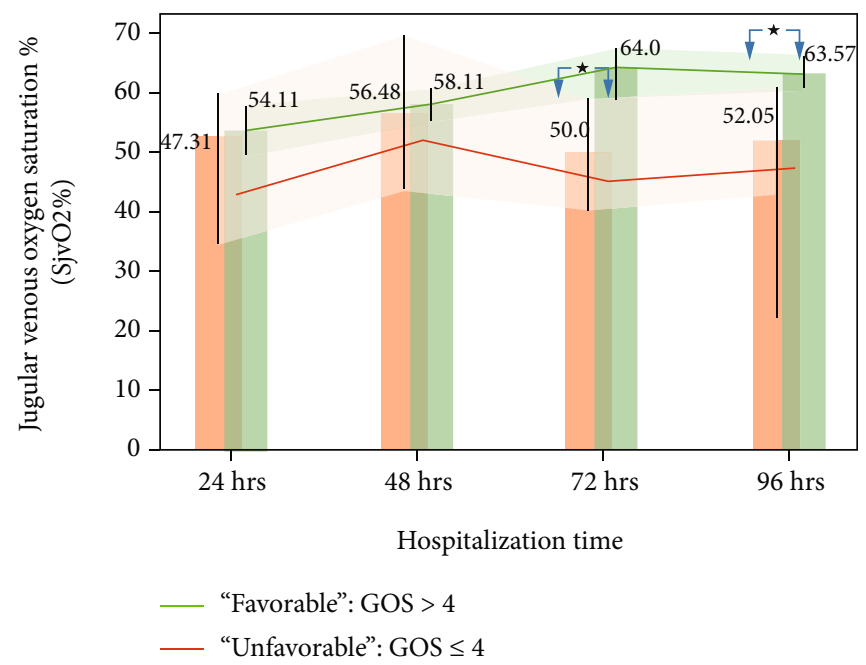

FIGURE 4: Changes in SjvO2\% stratified by GOS as a function of hospitalization time. Whiskers represent the standard error; above the bar are the mean values at the specific time. Red arrows correspond to statistically significant changes between measurements at specific times in "unfavorable" group. Green arrows correspond to statistically significant changes between measurements at specific times in "favourable" group. Shaded regions correspond to $95 \%$ confidence intervals for "unfavorable" group, red, and "favorable" group, green. * refers to $P<$ 0.01 .

21.15. UG was defined by PI levels greater than 1.94 at the end of the first day of hospitalization. There was a clear demarcation in PI between UG and FG. This observation is in agreement with other reports [59-61].

We also confirmed high mortality in patients with elevated PI. Moreno et al. [62] reported 83\% mortality for patients with an initial PI $>1.5$ and $100 \%$ for those with an initial PI $>2.6$. Though mortality in patients with $\mathrm{PI}>1.57$ was only $27 \%$, it is still an important factor in TBI treatment. Thus, the complexity of the problem did not allow us to speculate on the causes of the observed mortality differences.

Analysis of the rate of decrease in PI indicated that the time required to reach the normal threshold was $74 \mathrm{~h}$ longer in UG than in FG. Therefore, PI levels in UG would have required 7 days to reach the "safe zone," while PI levels in FG dropped significantly after $24 \mathrm{~h}$ of hospitalization, resulting in mean PI values below the threshold equal to 1.5.

Analysis of jugular venous oximetry (SjvO2\%), a measurement of the balance between metabolic demand, cerebral oxygen supply, and cerebral metabolic demand [63, 64] in patients with TBI, allows assessment of the severity of trauma, including cerebral hypoperfusion or ischemia
[65-67]. Although a recent study showed normal SjvO2\% between 44.7 and $69.5 \%$ [63], the generally accepted range is between 55 and $75 \%$ [68]. Thus, for discussion purposes, we employ the latter.

This study showed SjvO2\% near and above 55\% for nearly all patients in FG. Furthermore, there was an increase in $\mathrm{SjvO} 2 \%$ at a rate of $0.13 \% / \mathrm{h}$ from 24 to $96 \mathrm{~h}$. UG was delineated by an SjvO2\% below 55\% and a minuscule rate of change of $0.06 \% / \mathrm{h}$, reflecting, most probably, irreversible ischemic desaturation. Furthermore, the mortality rate rendered by unfavorable SjvO2\% was greater than previously reported [66]: $27 \%$ versus $17 \%$.

An amalgam of this and a previous study [69] indicates that SjvO2\% may be used to optimize TBI treatment. However, when evaluating the positive influence of an increase in SjvO2\%, caution must be exercised. Yokota et al. [70] showed that the mortality rate is a function of a dramatic increase in the $\mathrm{SjVO} 2 \%$ level, reaching $100 \%$ for cases defined by an SjvO2\% greater than $90 \%$ above the standard threshold. Unfortunately, we were unable to assess the minimum rate of increase in $\mathrm{SjvO} 2 \%$, resulting in a detrimental result. 
An analysis of correlations between the parameters studied indicated that FG was defined by a statistically significant decrease in S100B protein levels correlated with a statistically significant decrease in PI and a small increase in SjVO2\%. Furthermore, all parameters were within nonpathological ranges within 6 days of the patient's admission. The changes observed in the UG were in the same direction but of greater magnitude than those in the FG. The levels of the respective parameters were significantly higher in UG than in FG and did not reach "normality" for at least 7 days after the patient's admission.

\section{Conclusions}

In conclusion, mortality and morbidity rates in patients with TBI can be assessed within the first 4 days after hospitalization using S100B protein and PI levels and SjVO2\%. Extension of the presented research should lead to the development of improved personalized TBI treatment, greatly increasing the chance of patient survival.

\section{Data Availability}

Data are provided on request.

\section{Conflicts of Interest}

The authors declare that they have no conflicts of interest.

\section{Authors' Contributions}

S.D. and M.Z. carried out the experiment. S.D. wrote the manuscript with support from R.T. R.T., A.Z., and M.Z. helped supervise the project. R.T., S.D., A.Z., and M. Z conceived the original idea.

\section{Acknowledgments}

Research reported in this publication was supported by the Commission for Scientific Research of the Medical Centre for Postgraduate Education in Warsaw, Poland, research grant no. 501-2-1-20-49/04 (SD), and by the Kazimierz Pulaski University of Technology and Humanities Radom, Faculty of Medical Sciences and Health Sciences, Radom, Poland (RT), research grants 3529/188/P and DBUPB/2021/028.

\section{References}

[1] M. C. Dewan, A. Rattani, S. Gupta et al., "Estimating the global incidence of traumatic brain injury," Journal of Neurosurgery JNS, vol. 130, no. 4, pp. 1080-1097, 2019.

[2] A. P. Romodanov and E. G. Pedachenko, "Features of the clinical manifestation of contusion of the cerebral hemisphere in patients with hypertension," Zhurnal Voprosy Neirokhirurgii Imeni N. N. Burdenko, vol. 3, pp. 3-6, 1983.

[3] D. Toccalino, A. Colantonio, and V. Chan, "Update on the epidemiology of work-related traumatic brain injury: a systematic review and meta-analysis," Occupational and Environmental Medicine, 2021.
[4] J. Berg, F. Tagliaferri, and F. Servadei, "Cost of trauma in Europe," European Journal of Neurology, vol. 12, Suppl 1, pp. 85-90, 2005.

[5] G. Chappuis, B. Soltermann, A. Cea, and Ceredoc, "Number and cost of claims linked to minor cervical trauma in Europe: results from the comparative study by CEA, AREDOC and CEREDOC," European Spine Journal, vol. 17, no. 10, pp. 1350-1357, 2008.

[6] H. C. Pape, E. Neugebauer, S. A. Ridley, O. Chiara, T. G. Nielsen, and M. C. Christensen, "Cost-drivers in acute treatment of severe trauma in Europe: a systematic review of literature," European Journal of Trauma and Emergency Surgery, vol. 35, no. 1, pp. 61-66, 2009.

[7] A. Dadas, J. Washington, R. Diaz-Arrastia, and D. Janigro, "Biomarkers in traumatic brain injury (TBI): a review," Neuropsychiatric Disease and Treatment, vol. Volume 14, pp. 29893000, 2018.

[8] Z. S. Gan, S. C. Stein, R. Swanson et al., "Blood biomarkers for traumatic brain injury: a quantitative assessment of diagnostic and prognostic accuracy," Frontiers in Neurology, vol. 10, pp. 446-446, 2019.

[9] S. Purkayastha and F. Sorond, "Transcranial Doppler ultrasound: technique and application," Seminars in Neurology, vol. 32, no. 4, pp. 411-420, 2013.

[10] M. Smith, “Cerebral perfusion pressure,” BJA: British Journal of Anaesthesia, vol. 115, no. 4, pp. 488-490, 2015.

[11] G. Teasdale and B. Jennett, "Assessment of coma and impaired consciousness. A practical scale," Lancet, vol. 304, no. 7872, pp. 81-84, 1974.

[12] L. F. Marshall, S. B. Marshall, M. R. Klauber et al., "The diagnosis of head injury requires a classification based on computed axial tomography," Journal of Neurotrauma, vol. 9, Supplement 1, pp. S287-S292, 1992.

[13] C. J. Rao, P. K. Shukla, S. Mohanty, and Y. J. Reddy, "Predictive value of serum lactate dehydrogenase in head injury," Journal of Neurology, Neurosurgery, and Psychiatry, vol. 41, no. 10, pp. 948-953, 1978.

[14] M. C. Liu, V. Akle, W. Zheng et al., "Extensive degradation of myelin basic protein isoforms by calpain following traumatic brain injury," Journal of Neurochemistry, vol. 98, no. 3, pp. 700-712, 2006.

[15] S. A. Ross, R. T. Cunningham, C. F. Johnston, and B. J. Rowlands, "Neuron-specific enolase as an aid to outcome prediction in head injury," British Journal of Neurosurgery, vol. 10, no. 5, pp. 471-476, 1996.

[16] I. M. Skogseid, H. K. Nordby, P. Urdal, E. Paus, and F. Lilleaas, "Increased serum creatine kinase $\mathrm{BB}$ and neuron specific enolase following head injury indicates brain damage," Acta Neurochirurgica, vol. 115, no. 3-4, pp. 106-111, 1992.

[17] A. Harris, S. Keuler, A. Kerska, and M. Rogatzki, "Serum Protein S100B, a Biomarker for Head Injury or Skeletal Muscle Damage?," The FASEB Journal, vol. 31, no. S1, 2017.

[18] S. Korfias, G. Stranjalis, A. Papadimitriou et al., "Serum S-100B protein as a biochemical marker of brain injury: a review of current concepts," Current Medicinal Chemistry, vol. 13, no. 30, pp. 3719-3731, 2006.

[19] O. Savola, J. Pyhtinen, T. K. Leino, S. Siitonen, O. Niemelä, and M. Hillbom, "Effects of head and extracranial injuries on serum protein S100B levels in trauma patients," The Journal of Trauma, vol. 56, no. 6, pp. 1229-1234, 2004. 
[20] R. Donato, B. R. Cannon, G. Sorci et al., "Functions of S100 proteins," Current Molecular Medicine, vol. 13, no. 1, pp. 2457, 2013.

[21] G. Sorci, F. Riuzzi, C. Arcuri et al., "S100B protein in tissue development, repair and regeneration," World Journal of Biological Chemistry, vol. 4, no. 1, pp. 1-12, 2013.

[22] N. Fatima, A. Shuaib, T. S. Chughtai, A. Ayyad, and M. Saqqur, "The role of transcranial Doppler in traumatic brain injury: a systemic review and meta-analysis," Asian journal of neurosurgery, vol. 14, no. 3, pp. 626-633, 2019.

[23] G. D. Murray, I. Butcher, G. S. McHugh et al., "Multivariable prognostic analysis in traumatic brain injury: results from the IMPACT study," Journal of Neurotrauma, vol. 24, no. 2, pp. 329-337, 2007.

[24] E. W. Steyerberg, N. Mushkudiani, P. Perel et al., "Predicting outcome after traumatic brain injury: development and international validation of prognostic scores based on admission characteristics," PLoS Medicine, vol. 5, no. 8, 2008.

[25] A. I. Maas, M. Dearden, G. M. Teasdale et al., "EBIC-guidelines for management of severe head injury in adults. European Brain Injury Consortium," Acta Neurochirurgica, vol. 139, no. 4, pp. 286-294, 1997.

[26] R. G. Gosling and D. H. King, The Role of Measurement in Peripheral Vascular Surgery: Arterial Assessment by DopplerShift Ultrasound, vol. 67, no. 6P1, 1974SAGE Publications, 1974.

[27] M. Saculinggan and E. A. Balase, "Empirical power comparison of goodness of fit tests for normality in the presence of outliers," Journal of Physics: Conference Series, vol. 435, article 012041, 2013.

[28] M. R. Chernick, W. González-Manteiga, R. M. Crujeiras, and E. B. Barrios, Bootstrap methods, M. Lovric, Ed., In International Encyclopedia of Statistical Science, Berlin, Heidelberg: Springer Berlin Heidelberg, 2011.

[29] M. Kay and J. Wobbrock, "ARTool: aligned rank transform for nonparametric factorial ANOVAs," R package version, vol. 10, 2016.

[30] B. Jennett and M. Bond, "Assessment of outcome after severe brain damage: a practical scale," The Lancet, vol. 305, no. 7905, pp. 480-484, 1975.

[31] J. Y. Jiang, G. Y. Gao, W. P. Li, M. K. Yu, and C. Zhu, "Early indicators of prognosis in 846 cases of severe traumatic brain injury," Journal of Neurotrauma, vol. 19, no. 7, pp. 869-874, 2002.

[32] J. F. Kraus and D. L. McArthur, "Epidemiologic aspects of brain injury," Neurologic Clinics, vol. 14, no. 2, pp. 435-450, 1996.

[33] H. Lingsma, T. M. Andriessen, I. Haitsema et al., "Prognosis in moderate and severe traumatic brain injury," Journal of Trauma and Acute Care Surgery, vol. 74, no. 2, pp. 639-646, 2013.

[34] A. I. Maas and E. W. Steyerberg, "Monitoring prognosis in severe traumatic brain injury," Critical Care, vol. 18, no. 3, p. 150, 2014.

[35] E. Mercier, A. Boutin, F. Lauzier et al., "Predictive value of S100beta protein for prognosis in patients with moderate and severe traumatic brain injury: systematic review and metaanalysis," BMJ, vol. 346, no. apr 4 1, p. 1757, 2013.

[36] J. A. Myburgh, D. J. Cooper, S. R. Finfer et al., "Epidemiology and 12-month outcomes from traumatic brain injury in Aus- tralia and New Zealand," The Journal of Trauma, vol. 64, no. 4, pp. 854-862, 2008.

[37] M. C. Pace, G. Cicciarella, E. Barbato et al., "Severe traumatic brain injury: management and prognosis," Minerva Anestesiologica, vol. 72, no. 4, pp. 235-242, 2006.

[38] B. Roozenbeek, H. F. Lingsma, F. E. Lecky et al., "Prediction of outcome after moderate and severe traumatic brain injury: external validation of the International Mission on Prognosis and Analysis of Clinical Trials (IMPACT) and Corticoid Randomisation After Significant Head injury (CRASH) prognostic models," Critical Care Medicine, vol. 40, no. 5, pp. 1609-1617, 2012.

[39] S. Thornhill, G. M. Teasdale, G. D. Murray, J. McEwen, C. W. Roy, and K. I. Penny, "Disability in young people and adults one year after head injury: prospective cohort study," $B M J$, vol. 320, no. 7250, pp. 1631-1635, 2000.

[40] M. S. Xydakis, G. S. Ling, L. P. Mulligan, C. H. Olsen, and W. C. Dorlac, "Epidemiologic aspects of traumatic brain injury in acute combat casualties at a major military medical center: a cohort study," Annals of Neurology, vol. 72, no. 5, pp. 673-681, 2012.

[41] N. Golden, T. G. B. Mahadewa, C. Aryanti, and I. P. E. Widyadharma, "S100B serum level as a mortality predictor for traumatic brain injury: a meta-analysis," Open access Macedonian journal of medical sciences, vol. 6, no. 11, pp. 22392244, 2018.

[42] A. Goyal, M. D. Failla, C. Niyonkuru et al., "S100b as a prognostic biomarker in outcome prediction for patients with severe traumatic brain injury," Journal of Neurotrauma, vol. 30, no. 11, pp. 946-957, 2013.

[43] S. Kahouadji, P. Salamin, L. Praz et al., "S100B blood level determination for early management of ski-related mild traumatic brain injury: a pilot study," Frontiers in Neurology, vol. 11 , no. $856,2020$.

[44] E. P. Thelin, D. W. Nelson, and B.-M. Bellander, "A review of the clinical utility of serum S100B protein levels in the assessment of traumatic brain injury," Acta Neurochirurgica, vol. 159, no. 2, pp. 209-225, 2017.

[45] N. Fisher and P. Hall, "Bootstrap algorithms for small samples," Journal of Statistical Planning and Inference, vol. 27, no. 2, pp. 157-169, 1991.

[46] P. Hall, The Bootstrap and Edgeworth Expansion, Springer Series in Statistics, Springer-Verlag, New York, 1992.

[47] L. M. Gerber, Y. L. Chiu, N. Carney, R. Hartl, and J. Ghajar, "Marked reduction in mortality in patients with severe traumatic brain injury," Journal of Neurosurgery, vol. 119, no. 6, pp. 1583-1590, 2013.

[48] A. Raabe and V. Seifert, "Protein S-100B as a serum marker of brain damage in severe head injury: preliminary results," Neurosurgical Review, vol. 23, no. 3, pp. 136-138, 2000.

[49] R. Aaslid, T. M. Markwalder, and H. Nornes, "Noninvasive transcranial Doppler ultrasound recording of flow velocity in basal cerebral arteries," Journal of Neurosurgery, vol. 57, no. 6, pp. 769-774, 1982.

[50] K. H. Chan, N. M. Dearden, and J. D. Miller, "Transcranial Doppler-sonography in severe head injury," Acta Neurochirurgica. Supplementum (Wien), vol. 59, pp. 81-85, 1993.

[51] K. Jarus-Dziedzic, W. Zub, and Z. Czernicki, "The application of transcranial Doppler sonography in the evaluation of cerebral flow disturbances after head trauma," Neurologia i Neurochirurgia Polska, vol. 33, no. 1, pp. 151-167, 1999. 
[52] M. Weber, P. Grolimund, and R. W. Seiler, "Evaluation of posttraumatic cerebral blood flow velocities by transcranial Doppler ultrasonography," Neurosurgery, vol. 27, no. 1, pp. 106-112, 1990.

[53] K. H. Chan, J. D. Miller, and N. M. Dearden, "Intracranial blood flow velocity after head injury: relationship to severity of injury, time, neurological status and outcome," Journal of Neurology, Neurosurgery, and Psychiatry, vol. 55, no. 9, pp. 787-791, 1992.

[54] K. Kinoshita, "Traumatic brain injury: pathophysiology for neurocritical care," Journal of Intensive Care, vol. 4, no. 1, pp. 29-29, 2016.

[55] S. M. Dzierzecki, unpublished results.

[56] T. Chang, L. Li, Y. Yang, M. Li, Q. Yan, and L. Gao, “Transcranial Doppler ultrasonography for the management of severe traumatic brain injury after decompressive craniectomy," World Neurosurgery, vol. 126, pp. e116-e124, 2019.

[57] N. de Riva, K. Budohoski, P. Smielewski et al., "Transcranial Doppler pulsatility index: what it is and what it isn't," Neurocritical Care, vol. 17, no. 1, pp. 58-66, 2012.

[58] C. Ract, S. Le Moigno, N. Bruder, and B. Vigué, “Transcranial Doppler ultrasound goal-directed therapy for the early management of severe traumatic brain injury," Intensive Care Medicine, vol. 33, no. 4, pp. 645-651, 2007.

[59] B. K. Ojha, D. K. Jha, S. S. Kale, and V. S. Mehta, “Trans-cranial Doppler in severe head injury: evaluation of pattern of changes in cerebral blood flow velocity and its impact on outcome," Surgical Neurology, vol. 64, no. 2, pp. 174-179, 2005, discussion 179.

[60] H. Tan, H. Feng, L. Gao, G. Huang, and X. Liao, "Outcome prediction in severe traumatic brain injury with transcranial Doppler ultrasonography," Chinese Journal of Traumatology, vol. 4, no. 3, pp. 156-160, 2001.

[61] S. G. Voulgaris, M. Partheni, H. Kaliora, N. Haftouras, I. S. Pessach, and K. S. Polyzoidis, "Early cerebral monitoring using the transcranial Doppler pulsatility index in patients with severe brain trauma," Med Sci Monit, vol. 11, no. 2, 2005.

[62] J. A. Moreno, E. Mesalles, J. Gener et al., "Evaluating the outcome of severe head injury with transcranial Doppler ultrasonography," Neurosurgical Focus, vol. 8, no. 1, article e8, pp. 17, 2000.

[63] A. Chieregato, F. Calzolari, G. Trasforini, L. Targa, and N. Latronico, "Normal jugular bulb oxygen saturation," Journal of Neurology, Neurosurgery, and Psychiatry, vol. 74, no. 6, pp. 784-786, 2003.

[64] E. L. Gibbs, W. G. Lennox, L. F. Nims, and F. A. Gibbs, “Arterial and cerebral venous blood. Arterial-venous differences in man," The Journal of Biological Chemistry, vol. 144, no. 2, pp. 325-332, 1942.

[65] J. Cruz, "The first decade of continuous monitoring of jugular bulb oxyhemoglobinsaturation: management strategies and clinical outcome," Critical Care Medicine, vol. 26, no. 2, pp. 344-351, 1998.

[66] S. P. Gopinath, C. S. Robertson, C. F. Contant et al., "Jugular venous desaturation and outcome after head injury," Journal of Neurology, Neurosurgery, and Psychiatry, vol. 57, no. 6, pp. 717-723, 1994.

[67] C. S. Robertson, S. P. Gopinath, J. C. Goodman, C. F. Contant, A. B. Valadka, and R. K. Narayan, "SjvO2 monitoring in headinjured patients," Journal of Neurotrauma, vol. 12, no. 5, pp. 891-896, 1995.
[68] D. K. Dastur, M. H. Lane, D. B. Hansen et al., Effects of aging on cerebral circulation and metabolism in man, In Human aging: A biological and behavioral study, Bethesda, MD, US: US Dept of Health, Education, \& Welfare, 1963.

[69] J. Tyrak, I. Goscinski, M. Moskala, W. Traczewski, R. Witkowska, and J. Andres, "Experiments in evaluation of brain oxygenation and metabolism based on continuous bilateral $\mathrm{SjO} 2$ monitoring and metabolic glucose transformations in patients after severe cranio-cerebral injuries," Folia Medica Cracoviensia, vol. 42, no. 4, pp. 97-107, 2001.

[70] H. Yokota, Y. Yamamoto, M. Nakabayashi et al., “Continuous monitoring of jugular venous oxygen saturation in neurosurgical intensive care units," in Neurochemical Monitoring in the Intensive Care Unit, T. Tsubokawa, Ed., Springer-Verlag, Tokyo, 1995. 